\title{
AWARENESS OF FAMILY PLANNING AMONGST ANTENATAL PATIENTS IN A NIGERIAN COMMUNITY: AN EXPLORATORY STUDY
}

\author{
C.O. Omolase ${ }^{1}$, S.O. Faturoti ${ }^{2}$ and B.O. Omolase ${ }^{3}$
}

1. Department of Ophthalmology, Federal Medical Centre, Owo, Ondo State, Nigeria

2. Department of O \& G, Federal Medical Centre, Owo, Ondo State, Nigeria

3. Department of Medicine, Federal Medical Centre, Owo, Ondo State, Nigeria

Correspondence:

Dr. Omolase Charles Oluwole, Department of Ophthalmology, Federal Medical Centre, P.M.B 1053, Owo, Ondo State

Nigeria

E mail: omolash2000@yahoo.com.

\begin{abstract}
Aim: This study aimed at determining the awareness about family planning amongst pregnant women presenting to the antenatal clinic of Federal Medical Centre, Owo, Ondo State, Nigeria.

Methodology: The study was conducted between December, 2007 and February, 2008 at the antenatal clinic of the hospital. Ethical clearance was obtained from the Ethical Review Committee of the hospital prior to commencement of the study. The information was obtained from the respondents with the aid of a pre-tested semi-structured questionnaire which included their bio-data, awareness and the sources of awareness about family planning .Other information obtained were reasons for family planning as well as knowledge about the different methods of family planning. The information obtained with the study instrument (questionnaire) was collated and analyzed with SPSS statistical software version 12.0.1.

Results: Most respondents (89\%) were aware of family planning. The majority of the respondents:42 $(47.2 \%)$ received information about family planning from health workers while $21(23.6 \%)$ received the information through the media. Most of the respondents (74\%) knew about condom. The level of education significantly affected the awareness about family planning with a $\mathrm{p}$ value of 0.017 .

Conclusion: Most respondents were aware of family planning. The media should play a more prominent role in creating awareness amongst the populace about family panning.
\end{abstract}

Keywords: Family planning, awareness, pregnant women, Nigeria.

\section{INTRODUCTION}

Family planning implies the ability of individuals and couples to anticipate and attain their desired number of children by spacing and timing their births. It is achieved through the use of contraceptive methods and the treatment of involuntary infertility. The availability of family planning does more than enable women and men to limit family size. It safeguards individual health and rights, and improves the quality of life of couples and their children. Family planning is an important strategy in promoting maternal and child health. ${ }^{1}$ It improves health through adequate spacing of births and avoiding pregnancy at high risk maternal ages and parities. The most important proximate determinant of fertility is the use of family planning. ${ }^{2}$ Where contraceptive use is widespread fertility is low. Rajaretnam has demonstrated that even if there is no reduction in the family size of individual couples, delaying child bearing will bring about a decline in fertility and population growth rate. ${ }^{2}$ Lack of adequate information and ignorance are key factors militating against family planning practice in Nigeria. ${ }^{3}$ Many potential informational barriers exist to contraceptive use. Women must be aware of the methods available, must know where supplies of these methods can be obtained and they must know how to use the method they choose. ${ }^{4}$ Each year an estimated 500,000 women die of complications due to pregnancy, child bearing or unsafe abortion..$^{5-8}$

In some areas of Nigeria, one in five women report having experienced an unwanted conception, of these $58 \%$ had an abortion and an additional $9 \%$ attempted unsuccessfully to end the pegnancy. ${ }^{9}$ It is estimated that about $25 \%$ of women who have abortion in Nigeria 
experience serious complications. ${ }^{10}$ Adoption of family planning measures will reduce unwanted pregnancies and criminal abortions to its barest minimum. Pregnancy is the main reason that women in the reproductive age group die at a higher rate than men. ${ }^{11}$ Most maternal deaths occur among poor women who live in remote rural areas and have difficult access to hospital. ${ }^{7,12}$

In the light of the above, this study was designed to assess the awareness of family planning amongst antenatal patients at Federal Medical Centre, Owo, Ondo State, Nigeria.

\section{METHODOLOGY}

This is a descriptive cross - sectional study that was conducted between December, 2007 and February, 2008 at the antenatal clinic of Federal Medical Centre, Owo, Ondo State, Nigeria.

Ethical clearance was obtained from the Ethical Review Committee of the hospital prior to commencement of this study. One hundred consenting pregnant women were enrolled in this study. Informed consent was obtained from each of the respondents. The respondents were interviewed by the authors and three trained assistants with the aid of a pre-tested semi-structured questionnaire. Information obtained with the aid of the study instrument (questionnaire) included the bio - data of the respondents such as age, occupation, marital status, religion and ethnicity. We also established awareness about family planning, sources of awareness and knowledge of the different methods of family planning. The data obtained was collated and analyzed with SPSS statistical soft ware version 12.0.1. Cross tabulation of education and awareness about family planning was also done with chi-square table and statistical significance was set at $\mathrm{p}$ equals or less than 0.05 .

\section{RESULTS}

One hundred respondents participated in this study. The ages of the respondents ranged from 18 years to 39 years. The ethnicity of the respondents revealed that majority $(88 \%)$ of them were Yorubas while $9 \%$ were Ibos and the other ethnic groups accounted for the remaining 3\%.The respondents comprised of 87 Christians and 13 Muslims. Half of the respondents (50\%) had tertiary education, $42 \%$ had secondary education while the remaining $8 \%$ had primary education. Majority of the respondents $(92 \%)$ were married, 6\% were single and 2\% were widowed. As shown in Table 1 , most respondents were traders $(34 \%)$.

\begin{tabular}{|l|c|c|}
\hline OCOUPATION & FREQUENCY & PERCENTAGE(\%) \\
\hline Trading & 34 & 34 \\
\hline Schooling & 22 & 22 \\
\hline Givil service & 14 & 14 \\
\hline Teaching & 22 & 22 \\
\hline Artisan & 7 & 7 \\
\hline Journalism & 1 & 1 \\
\hline TOTAL & $\mathbf{1 0 0}$ & $\mathbf{1 0 0}$ \\
\hline
\end{tabular}

Table 1: Occupation of the respondents

The majority of the respondents (89\%) were aware of family planning while the remaining $11 \%$ were not aware. As detailed in Table 2, most respondents: 42 $(47.2 \%)$ received information about family planning from health workers.

\begin{tabular}{|l|l|l|}
\hline SOURCE & FREQUENCY & PERCENTAGE (\%) \\
\hline Health workers & 42 & 47.2 \\
\hline Media & 21 & 23.6 \\
\hline Lecture & 14 & 15.6 \\
\hline Friends & 5 & 5.6 \\
\hline Books & 7 & 7.9 \\
\hline TOTAL & $\mathbf{8 9}$ & $\mathbf{1 0 0}$ \\
\hline
\end{tabular}

Table 2: Source of awareness about family planning

Knowledge about the different methods of family planning are as indicated below, the percentages stated are the proportion of the respondents who knew about the different methods:

\begin{tabular}{|l|c|c|}
\hline REASONS & FREQUENCY & PERCENTAGE (\%) \\
\hline Plan size of family & 27 & 27 \\
\hline $\begin{array}{l}\text { Reduce maternal } \\
\text { death }\end{array}$ & 4 & 4 \\
\hline Economic reason & 18 & 18 \\
\hline $\begin{array}{l}\text { Prevent unwanted } \\
\text { pregnancy }\end{array}$ & 37 & 37 \\
\hline $\begin{array}{l}\text { Prevent over } \\
\text { population }\end{array}$ & 6 & 6 \\
\hline Education of children & 8 & 8 \\
\hline TOTAL & $\mathbf{1 0 0}$ & $\mathbf{1 0 0}$ \\
\hline
\end{tabular}

Table 3: Reasons why respondents considered family planning necessary

Oral contraceptive (17\%), IUCD (9\%), Condom (74\%), Injectable (29\%), Vasectomy (3\%), Withdrawal method (30\%) and Vagina foaming tablets $(16 \%)$. As detailed in Table 3 the reasons why respondents considered family planning necessary included prevention of unwanted pregnancy (37\%) and planning of family size $(27 \%)$ 
As shown in Table 4 the level of education significantly affected the awareness about family planning with a P-value of 0.017 .

\begin{tabular}{|l|c|c|c|}
\hline EDUCAIION & \multicolumn{2}{|c|}{ AWARENESS } & TOTAL \\
\hline & AWARE & NOTAWARE & \\
\hline Prinary & 8 & 0 & 8 \\
\hline Secondary & 33 & 9 & 42 \\
\hline Tertiary & 48 & 2 & 50 \\
\hline TOTAL & 89 & 11 & 10 \\
\hline
\end{tabular}

$\mathrm{P}$-Value $=0.017$

\section{Table 4 Fducationand awareness about family plaming}

\section{DISCUSSION}

The age range of our respondents is expected of women in the reproductive age group. The fact that the respondents were mostly Yorubas is expected as the community is a Yoruba community. Christianity been the predominant religion amongst the study population is also in tandem with the predominant religion in the study community.

The level of awareness about family planning in this study is higher than the finding of Adinma et al in Nnewi, Nigeria in which $76 \%$ of their respondents were aware of family planning. ${ }^{3}$ Our finding is also higher than that of another Nigerian study by OyeAdeniran et al in which $67.1 \%$ of their respondents were aware of family planning. ${ }^{13}$ The level of awareness about family planning established by Obisesan et al in Ibadan South-West, Nigeria was $94.3 \% .{ }^{14} \mathrm{~A}$ study conducted by Ijadunola in Ife, Nigeria revealed that awareness of family planning amongst sexually active lactating women was $95.5 \% .{ }^{15}$ The findings of these latter and former studies are consistent with that of an Indian study by Sharma et al in which $92.7 \%$ of their respondents were aware of family planning. ${ }^{16}$. The most common source of information about family planning in this study was health workers, this finding is however at variance with that of another Nigerian study by Ikechebelu et al in which the most common source of family planning information was the mass media.$^{17}$ The finding of this latter study brings to the fore the important role the mass media can play in spreading family planning information. Our finding is also at variance with that of Mao et al in India in which $44 \%$ of their study population got information about contraceptive methods through friends. ${ }^{18}$ However the importance of adequate health education of the populace by health workers cannot be overemphasized.An individual that is well informed about health issue will not hesitate to seek health care when the need arises. Thus the more knowledgeable people are about reproductive health the more likely are they to access family planning. The knowledge about family planning amongst the respondents was generally low. This finding is not impressive at all in view of the increasing rate of maternal mortality in Nigeria. This finding is however in keeping with that of Beekle et al in Ethiopia in which the knowledge and practice of contraception amongst their study population was very low. ${ }^{19}$

It is understandable that most of our respondents knew about condom in view of the intensive health education carried out in Nigeria amongst the populace on the practice of safe sex through the use of condom to curtail the spread of HIV-AIDS. The fact that the condom is cheap and readily available could also have contributed appreciably to the awareness about it. One is also not surprised that the level of education of the respondents significantly affected their level of awareness about family planning. This finding also established the importance of education as the more educated an individual is the more informed they are likely to be. The fact that all the respondents had at least primary education could also have contributed to their enthusiasm to access qualitative health care at the tertiary level of care. It is imperative for all concerned to intensify efforts to educate the populace most especially on health related issues such as family planning.

\section{CONCLUSION AND RECOMMENDATION}

\section{Conclusion}

Most respondents were aware of family planning and the main source of awareness was health workers. The level of education significantly affected the awareness about family planning. The knowledge about the different methods of family planning except condoms was generally low.

\section{Recommendation}

1 There is a need to create more awareness about family planning amongst the populace through health education.

2 The media should play a more prominent role in enlightening the populace about family planning.

\section{ACKNOWLEDGEMENT}

We glorify God for a successful completion of this work. Special thanks to the respondents for graciously accepting to participate in this study. The support of the management of Federal Medical Centre, Owo, Ondo State, Nigeria is hereby acknowledged.

\section{REFERENCES}

1. Umbeli T., Mukhtar A. and Abusalab M.A. Study of unmet needs for family planning in Dar Assalam Sudan 2001.E M H J 2005;11(4) 
2. Rajaretnam T. How delaying marriage and spacing births contribute to population control: An explanation with illustrations. J Fam Welfare 1990;34:3-13.

3. Adinma J.I.B., Nwosu B.O. Family planning knowledge and practice among Nigerian women attending an antenatal clinic. Adv contracept 2005;11(4):335-344.

4. Chandhick N., Dhillon B.S., Kambo I., Sexena N.C. Contraceptive knowledge, practices and utilization of services in rural areas of India (an ICMR task force study). 2003;57(70): 3003-10.

5. Herz B. and Measham A.R. The safe motherhood initiative proposals for action. Washington D.C. World bank 1987;52.

6. Winikoff B., Sulivan M. Assessing the role of family planning in reducing maternal mortality . Stud fam plann 1987; 18(3): 128-143.

7. World Health Organization (WHO).Prevention of maternal mortality. Report of WHO interregional meeting, Geneva, 11-15 November 1985,Geneva, WHO,1986:23.

8. WHO. Maternal mortality ratios and rates: a tabulation of available information. $3^{\mathrm{RD}}$ ed Geneva, WHO, 1991:100.

9. Okonofua F.E., Odimegwu C., Ajabor H., Daru P.H., Johnson A. Assessing the prevalence and determinants of unwanted pregnancy and induced abortion in Nigeria. Stud fam plann 1999; 30(1):6777.

10. Bankole A. Unwanted pregnancy and unsafe abortion in Nigeria: Causes and consequences, New York: Guttmacher Institute, 2006.

11. Maine D., Rosenfield A., Wallace M., Kimball A.M. et al. Prevention of maternal death in developing countries. Program options and practical considerations. (Prepared for the International Safe motherhood conference, Nairobi, Kenya) Feb 10-13 1987:50.

12. Royston E. and Amstong S. eds. Preventing maternal death. Geneva. World Health Organization 1989:223.

13. Oye-Adeniran B.A., Adewole I.F., Umoh A.V., Oladokun A., Gbadegesin A., Ekanem E.E. et al. Community based study of contraceptive behaviour in Nigeria. Afr J Rep Health 2006; 10(2): 90-104.

14. Obisesan K.A., Adeyemo A.A., Fakokunde B.O. Awareness and use of family planning methods among married women in Ibadan. Nigeria. East Afr Med J 1998; 75(3):135-138.

15. Ijadunola K.T., Orji E.O. and Ajibade F.O. Contraceptive awareness and use among sexually active breast feeding mothers in Ile-Ife,Nigeria. East Afr Med J 2005; 82(5):250-255.

16. Sharma B., Sharma S. and Nagar S. Awareness among women towards aspects of family planning in Kullu District of Himachal Pradesh. J Soc Sci 2005; 11(3):240-251.

17. Ikechebelu J.I., Joe-Ikechebelu N.N. and Obiajulu F.N. Knowledge, attitude and practice of family planning among Igbo women of SouthEastern Nigeria .J Obstet gynaecol 2005; 25(8) : 792-795.

18. Mao J. Knowledge, attitude and practice of family planning: A study of Tezu village, Manipur (India). The Internet Journal of Biological Anthropology 2007;1(1) : Accessed on line on $7^{\text {th }}$ March,2008.

19. Beekle A.T., McCabe C. Awareness and determinants of family planning practice in Jimma, Ethiopia. Int Nurs Rev 2006; 53(4): 269-276. 